\title{
Inhalt
}

Sondertagung $2021 \ldots \ldots \ldots \ldots \ldots \ldots \ldots \ldots \ldots \ldots \ldots \ldots \ldots \ldots \ldots \ldots \ldots$

Einziger Beratungsgegenstand:

\section{Staat und Gesellschaft in der Pandemie}

1. Relationale Freiheit. Grundrechte in der Pandemie

Referat von Anna Katharina Mangold . . . . . . . . . . . . . 7

Leitsätze der Referentin . . . . . . . . . . . ....... 31

2. Verwaltungsrecht der vulnerablen Gesellschaft

Referat von Stephan Rixen . . . . . . . . . . . ..... 37

Leitsätze des Referenten................... 63

3. Demokratie im Notstand? Rechtliche und epistemische

Bedingungen der Krisenresistenz der Demokratie

Referat von Matthias Mahlmann . . . . . . . . . . . . . . . . . . 69

Leitsätze des Referenten . . . . . . . . . . . . . . . . . . . . 101

4. Europa und die Pandemie. Zuständigkeitsdefizite

und Kooperationszwänge

Referat von Andreas Th. Müller . . . . . . . . . . . . . . . 105

Leitsätze des Referenten . . . . . . . . . . . . . . . . 136

5. Aussprache und Schlussworte . . . . . . . . . . . . 141

6. Corona als Motor: Transformationen und öffentliches Recht

Podiumsdiskussion mit Franz Merli (Moderation),

Klaus Ferdinand Gärditz, Hans Michael Heinig,

Gertrude Lübbe-Wolff und Armin Nassehi,

sowie Aussprache . . . . . . . . . . . . . . . . 175

Verzeichnis der Rednerinnen und Redner . . . . . . . . . . . . . 215

Verzeichnis der Mitglieder der Vereinigung

der Deutschen Staatsrechtslehrer e.V. . . . . . . . . . . . 217

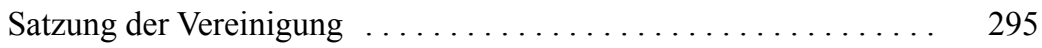


